\title{
CORRELATION OF PERCEIVED STRESS WITH SYMPTOM SEVERITY AND QUALITY OF LIFE IN TRICHOTILLOMANIA PATIENTS
}

\author{
Santanu Ghosh', Gautam Mazumder2, Surajit Bhattacharjee3, Anjana Bhattacharjee ${ }^{4}$ \\ ${ }_{1}^{1}$ Assistant Professor, Department of Psychiatry, Tripura Medical College, Agartala. \\ ${ }^{2}$ Associate Professor, Department of Dermatology, Tripura Medical College \& Dr. BRAM Teaching Hospital, Agartala. \\ ${ }^{3}$ Assistant Professor, Department of Molecular Biology \& Bioinformatics, Tripura University. \\ ${ }^{4}$ Assistant Professor, Department of Psychology, Tripura University.
}

\section{ABSTRACT}

Trichotillomania (TTM) is characterized by recurrent pulling out of one's hair resulting in noticeable hair loss. This study aims to evaluate the correlation of TTM symptom severity with the perceived stress along with the possible link between the quality of life and severity of Trichotillomania symptoms.

\section{MATERIALS AND METHODS}

This prospective study was conducted in Tripura Medical College since August 2011. Subjects were incorporated into the study from outpatient and inpatient clinics, referrals from clinicians of other specialty and different community outreach program. Total number of samples were $n=22$. Equal number of normal controls either from the accompanying persons of the patient or general population who consented to participate in the study. The controls were matched with the cases. Inclusion criteria: Patients who fulfil diagnostic criteria of trichotillomania. All trichotillomania patients irrespective of age and marital status were incorporated. Exclusion criteria: Trichotillomania patients having other dermatological diseases. Trichotillomania patients with psychosis and cognitive impairment or suffering from any organic illness.

\section{TOOLS USED}

Trichotillomania diagnostic interview revised for diagnosis of TTM, NIMH Trichotillomania Scales or Trichotillomania Symptom Severity Scale (NIMH-TSS) was used for assessment of symptom severity. Perceived Stress Scale by Sheldon Cohen and WHO QOLBREF was used for quality of life assessment.

\section{RESULT}

The NIHM-TSS score is negatively correlated with perceived stress score ( $\mathrm{r}=-0.19548)$. That means perceived stress is unrelated to symptoms severity of TTM. This is contrary to previous studies on this regard. In quality of life assessment, physical health (Domain 1) is negatively correlated with symptom severity of TTM ( $\mathrm{r}=-0.38916)$. On the other hand, in psychological health (Domain 2), social relationship (Domain 3) and environmental health (Domain 4) all three parameters are positively correlated with severity of symptoms in TTM.

\section{CONCLUSION}

The perceived stress is not related to symptom severity of Trichotillomania. More the perceived stress in trichotillomania patient, poor is the quality of life. More severe the symptom, poor is the physical quality of life. Psychological health, social relationship and environmental health all three parameters are positively correlated with severity of symptoms in TTM.

\section{KEYWORDS}

Hair Pulling, Trichotillomania, Impulse Control Disorder, Obsessive-Compulsive Spectrum Disorders, Hair-Loss, Quality of Life, Comorbidity.

HOW TO CITE THIS ARTICLE: Ghosh S, Mazumder G, Bhattacharjee S, et al. Correlation of perceived stress with symptom severity and quality of life in trichotillomania patients. J. Evolution Med. Dent. Sci. 2016;5(30):1518-1521, DOI: 10.14260/jemds/2016/358

\section{INTRODUCTION}

The word Trichotillomania (TTM) was coined by French dermatologist Francois Hallopeau. It is characterized by recurrent pulling out of one's hair resulting in noticeable hair loss.

Financial or Other, Competing Interest: None.

Submission 05-01-2016, Peer Review 06-01-2016,

Acceptance 11-01-2016, Published 12-04-2016.

Corresponding Author:

Dr. Gautam Mazumder

Associate Professor

Department of Dermatology,

Tripura Medical College \& Dr. B.R Ambedkar Memorial Teaching

Hospital, Hapania, Agartala-799014, P.O. ONGC Colony.

E-mail: drgautam2112@yahoo.com

DOI: $10.14260 /$ jemds $/ 2016 / 358$
There is sense of distress immediately before pulling out the hair or attempting to resist the behaviour. ${ }^{1}$ There is pleasure, gratification or relief during pulling out the hair. Chronic TTM is hallmarked by complex behaviours before, during and after epilation. The urge to pull customarily develops during solitary activity-relaxing, reading and watching television, for example. Alternately, it arises in the context of anxiety or frustration related to external stress. Some patients state that antecedent tingling or burning sensations in the scalp compel them to seek relief by pulling.

Trichotillomania was first recognized in the DSM-III-R. DSM-III-R classified trichotillomania as an impulse-control disorder, chiefly because of the typical cycle of mounting tension, the inability to resist the urge to pull hair and the release and gratification afterwards. 
DSM-IV then specifically excluded hair pulling secondary to medical conditions or other psychiatric disorders from the diagnosis. The criterion of significant distress or impairment in social, occupational or other important areas of functioning was added and was subsequently maintained in DSM-IV-TR in obsessive compulsive spectrum disorder whereas the fifth Edition (DSM-V), places trichotillomania in the category of obsessive-compulsive and related disorders. ICD-10 classifies trichotillomania under habit and impulse disorders, as a condition-characterized by noticeable hair loss due to a recurrent failure to resist impulses to pull out hairs, preceded by mounting tension and followed by a sense of relief or gratification. The diagnosis should not be made if-preexisting inflammation of the skin exists or if hair pulling occurs in response to a delusion or hallucination. Stereotyped movement disorder with hair-plucking (F98.4) is also specifically excluded. This problem brings clinically significant distress or impairment in social, occupational areas of life. ${ }^{2}$

Perceived stress means an individual's stress level, which depends on the way he/she perceives his/her present stressors. Stress is the mental, physical and emotional reactions that one experiences as a result of demands of one's life.

The present study aims to evaluate the correlation of TTM symptom severity with the perceived stress along with the possible link between the quality of life and severity of Trichotillomania symptoms.

\section{MATERIALS AND METHODS}

Sample selection: This prospective study was conducted in Tripura Medical College since August 2011. Subjects were incorporated into the study from outpatient and inpatient clinics, referrals from clinicians of other specialty and different community outreach program. Total number of samples were $n=22$. Equal number of normal controls either from the accompanying persons of the patient or general populations who consented to participate in the study. The controls were matched with the cases.

\section{Inclusion Criteria}

1. Patients who fulfil diagnostic criteria of trichotillomania (According to Trichotillomania Diagnostic InterviewRevised criteria).

2. Trichotillomania patients irrespective of age and marital status.

\section{Exclusion Criteria}

1. Trichotillomania patients having other dermatological diseases.

2. Trichotillomania patients with psychosis and cognitive impairment.

3. Patients suffering from any organic illness.

\section{Tools Used in Assessment}

1. Socio-Demographic Variables: A semi-structured interview schedule focused on personal characteristicsage, education, type of family, socioeconomic status was used which was prepared by Department of Psychiatry and Dermatology Tripura Medical College, Agartala.

2. Diagnostic Questionnaire: Trichotillomania Diagnostic Interview was done objectively trichotillomania depending on the DSM-IV TR criteria. ${ }^{1}$

3. Phenotype Assessment: The NIMH Trichotillomania Scales or Trichotillomania Symptom Severity Scale (NIMH-TSS) or Trichotillomania "Global" Scale. This is a globally validated scale developed by National Institute of Mental Health for checking the severity of trichotillomania. 3,4

4. Perceived Stress Scale. 5 - Developed by Sheldon Cohen (1983).

5. WHO QOL-BREF.6 was used for quality of life assessment.

\section{Clinical Assessment}

As most of the patients of trichotillomania presents with hair loss, they tend to present mostly in Dermatology OPD. The Dermatologist determined the dermatological comorbidities to rule out the presence of other dermatological conditions. Then diagnostic assessments were conducted by psychiatrists experienced with clinical evaluations of OCD. Clinicians used Trichotillomania Diagnostic Interview Revised Criteria as a semi-structured format for the evaluation of psychopathology. The symptom severity was measured by the NIMH Trichotillomania Scales or Trichotillomania Symptom Severity Scale (NIMH-TSS) or Trichotillomania-Global Scale for subjects who had received psychiatric treatment, consent was obtained to review relevant medical records, if such information was deemed useful for making diagnoses.

\section{Diagnostic Consensus Procedure}

Cases were reviewed independently by two expert diagnosticians who reviewed all case materials and completed a Diagnostic Assignment Checklist form. Any disagreements between the investigators were resolved before the case materials was edited and sent for data entry.

\section{Results and Interpretation}

The data were analysed using the Statistical Package for Social Science version 18.0 (IBM Corp., Somers, NY), and figures were plotted in GraphPad Prism version 5.0 (GraphPad Inc., San Diego, CA)

\section{Data Analysis for Patients}

\begin{tabular}{|c|c|c|c|c|}
\hline \multirow{2}{*}{ Variables } & \multicolumn{2}{|c|}{ TTM Cases } & \multicolumn{2}{c|}{ Control } \\
\cline { 2 - 5 } & $\begin{array}{c}\text { No. of Samples } \\
\mathbf{N = 2 2}\end{array}$ & $\mathbf{0}$ & $\begin{array}{c}\text { No. of Samples } \\
\text { N=22 }\end{array}$ & \% \\
\hline \multirow{2}{*}{ Sex } & Male:6 & 27.28 & Male:4 & 18.19 \\
& Female:16 & 72.72 & $34.91 \pm 11.37$ & 81.81 \\
\hline Age (Years) & $28.69 \pm 10.13$ & & 2 & 28.45 \\
\cline { 2 - 5 } & 4 & 18.19 & 15 & 9.09 \\
$20-45$ & 16 & 72.72 & 5 & 68.19 \\
& 2 & 9.09 & & 22.72 \\
\hline
\end{tabular}




\begin{tabular}{|c|c|c|c|c|}
\hline Education Level & 1 & 4.55 & 3 & 13.64 \\
Below Secondary & 3 & 13.63 & 14 & 63.64 \\
Secondary & 4 & 18.19 & 4 & 18.19 \\
Higher Secondary & 9 & 40.90 & 1 & 4.54 \\
Graduate & 5 & 22.73 & 0 & 0 \\
Post Graduate & 8 & 36.37 & 2 & 9.09 \\
\hline Marital Status & 13 & 59.09 & 20 & 90.91 \\
Unmarried & $1 \quad 4.54$ & 0 & 0 \\
Married & Table 1: Socio-demographic Characteristics \\
Separated & \multicolumn{2}{c}{} \\
\hline
\end{tabular}

\section{Socio-Demographic Variables}

The socio-demographic profile of the responders is given in Table 1.

\section{Age and Gender}

The mean age \pm SD of the cases (TTM patients) was $28.69 \pm 10.13$ years and the subjects in control group is $34.91 \pm 11.37$. There were $16(72.72 \%)$ female TTM patients and 18 female control participants participated in the study.

\section{Educational Level}

Among TTM patients, 1 (4.55\%) responders are educated up to below secondary level, $3(13.63 \%)$ responders are educated up to secondary level, $4(18.19 \%)$ are educated up to higher secondary level and $9(40.90 \%)$ responders are graduate. This can be interpreted that TTM are more diagnosed in educated patients. Probably, this is due to their awareness of the disease.

\section{Marital Status}

In our study sample there were $8(36.37 \%)$ unmarried, 13 (59.09\%) married and 1 (4.54\%) separated responders. It shows that most of the responders are married.

Correlation of TTM Symptom Severity with Perceived Stress and Quality of Life

\begin{tabular}{|c|c|c|}
\hline X-axis & Y-axis & Correlation Coefficient (r) \\
\hline NIHM-TSS & PSS & -0.19548 \\
\hline NIHM-TSS & QOL-D1 & -0.38916 \\
\hline NIHM-TSS & QOL-D2 & 0.08562 \\
\hline NIHM-TSS & QOL-D3 & 0.22688 \\
\hline NIHM-TSS & QOL-D4 & 0.1674 \\
\hline
\end{tabular}

The NIHM-TSS score is negatively correlated with perceived stress score ( $\mathrm{r}=-0.19548)$. That means perceived stress is unrelated to symptom severity of TTM. This is contrary to previous studies on this regard.

In quality of life assessment, physical health (Domain 1) is negatively correlated with symptom severity of TTM ( $\mathrm{r}=-$ 0.38916). On the other hand, in psychological health (Domain 2), social relationship (Domain 3) and environmental health (Domain 4), all three parameters are positively correlated with severity of symptoms in TTM.
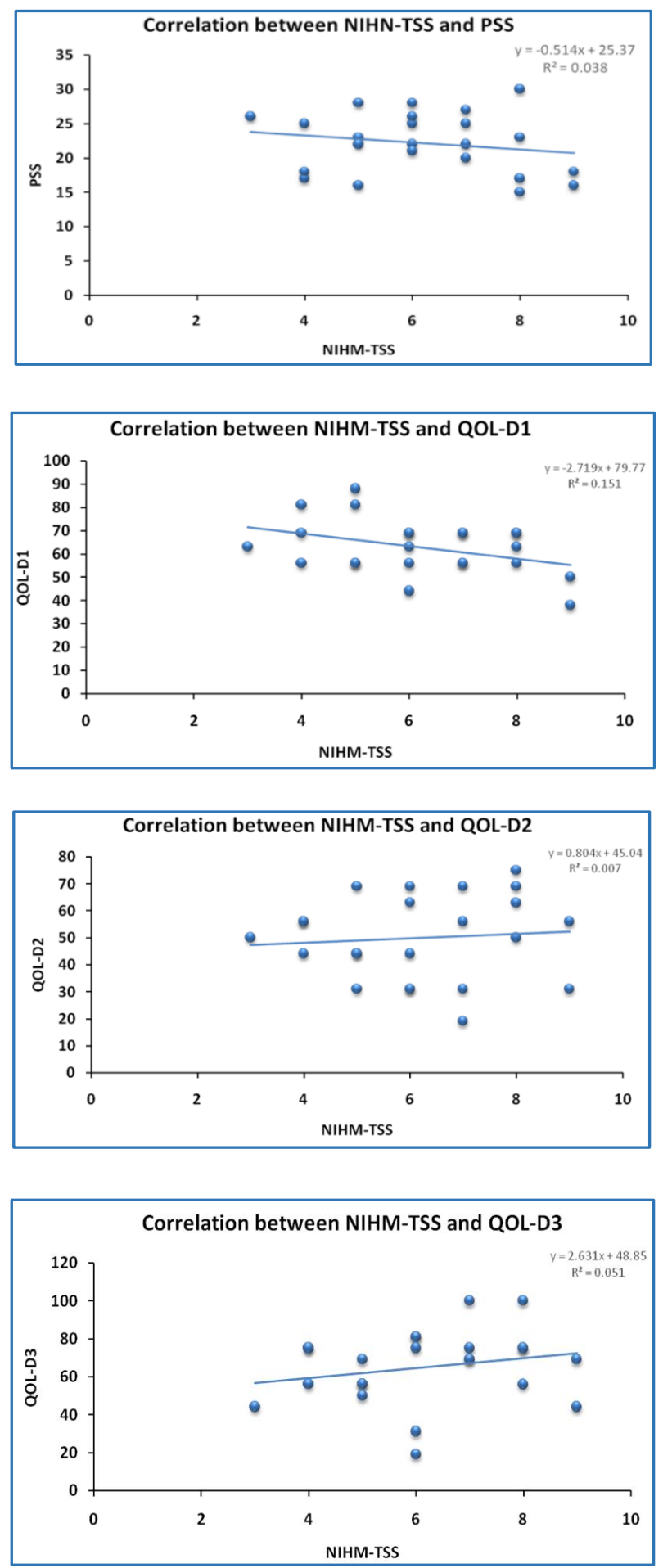


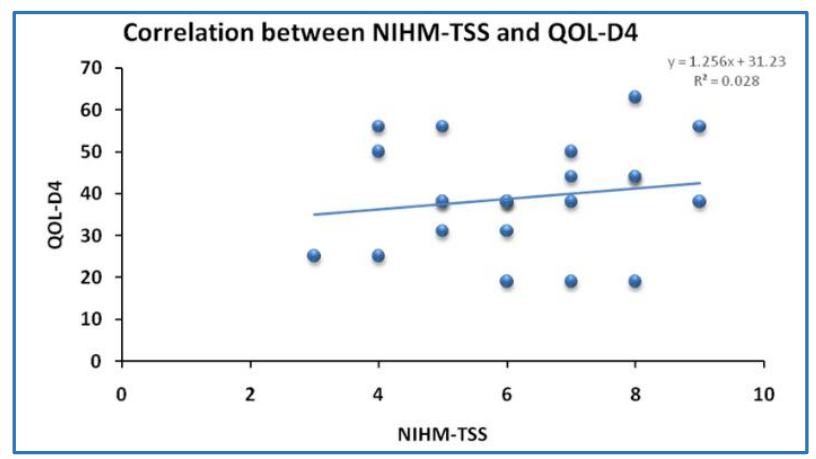

Relationship between the levels of QOL-D1, QOL-D2, QOL-D3, QOL-D4, PSS and NIHM-TSS. $r$ and $p$ : coefficient and significance level respectively, according to the Pearson correlation test.

\section{Analysis for Control Sets}

\begin{tabular}{|c|c|c|}
\hline X-axis & Y-axis & Correlation Coefficient (r) \\
\hline PSS & QOL-D1 & -0.34746 \\
\hline PSS & QOL-D2 & 0.3762 \\
\hline PSS & QOL-D3 & -0.16696 \\
\hline PSS & QOL-D4 & 0.4633 \\
\hline
\end{tabular}
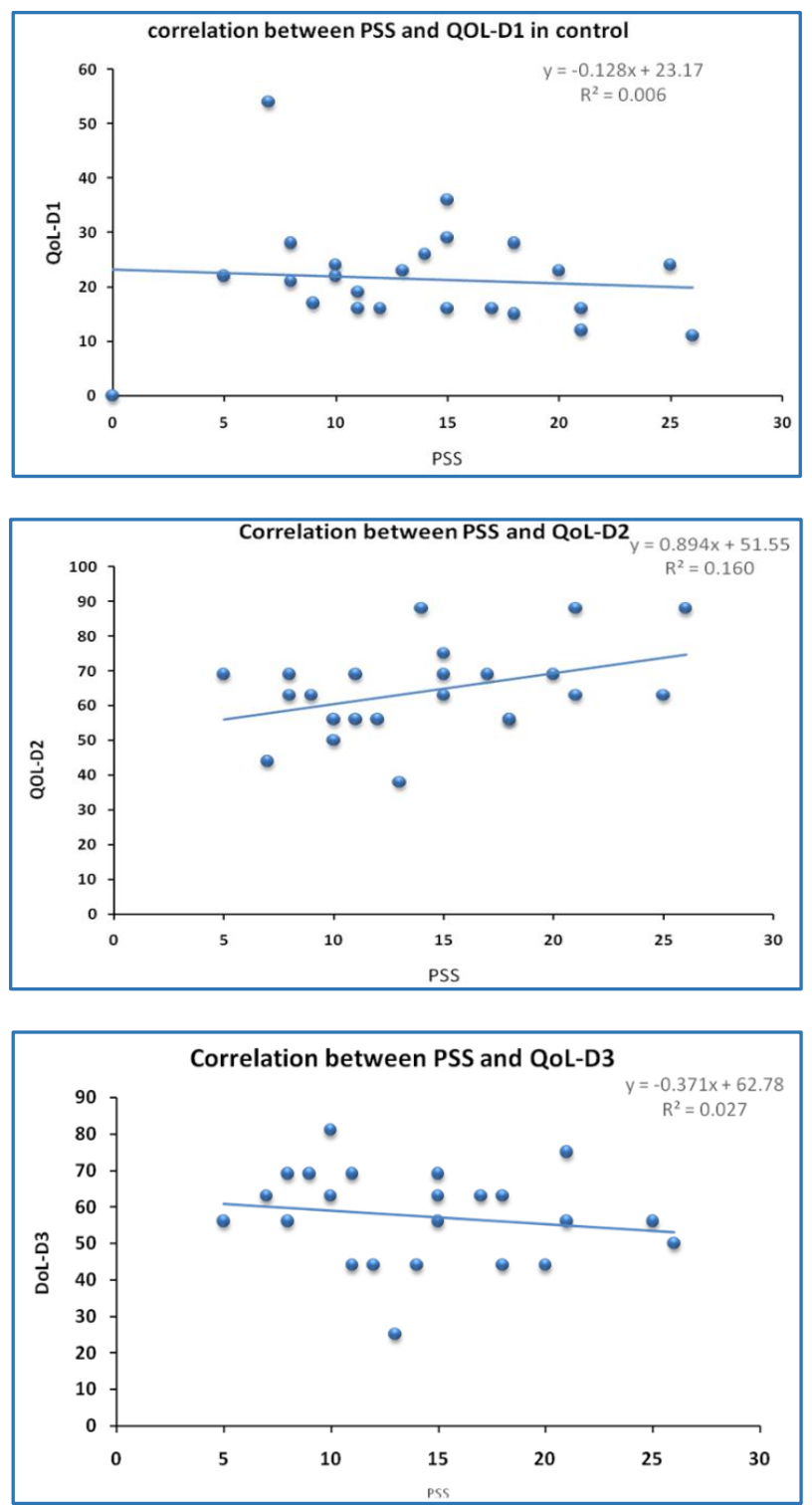

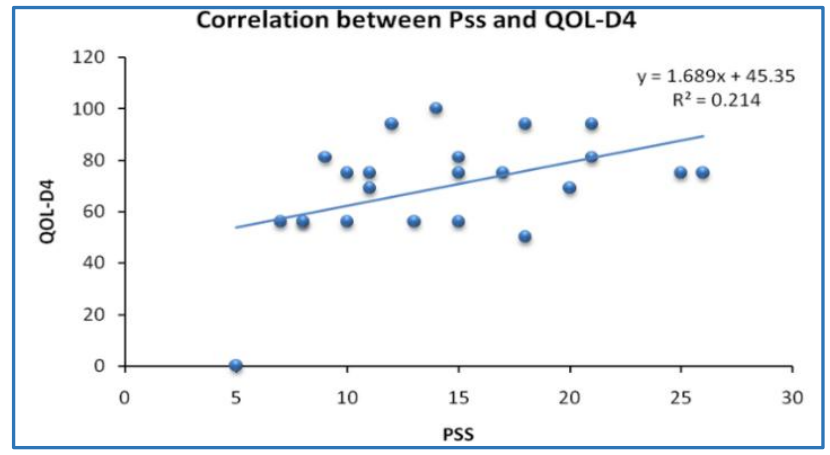

Relationship between the levels of QOL-D1, QOL-D2, QOL-D3, QOL-D4 and PSS. $r$ and $p$ : coefficient and significance level respectively, according to the Pearson correlation test.

\section{CONCLUSION}

The Following Conclusions can be drawn from our study:

1. The perceived stress is not related to symptom severity of trichotillomania.

2. More the perceived stress in trichotillomania patient, poor is the quality of life.

3. More severe the symptom, poor is the physical quality of life.

4. Psychological health, social relationship and environmental health all three parameters are positively correlated with severity of symptoms in TTM.

\section{Limitation of the Study}

As the number of cases is less, the result may not be generalised to all TTM patients.

\section{REFERENCES}

1. Winchel R. Trichotillomania. In: Widiger TA, Frances AJ, Pincus HA, et al. editors. DSM-IV Sourcebook. Washington, DC: American Psychiatric Association. 1997;3:303-15.

2. Dan J Stein, Grant JE, Franklin ME, et al. Trichotillomania (hair pulling disorder), skin picking disorder, and stereotypic movement disorder: toward DSM-V. Depression and anxiety 2010;27(6):611-26.

3. Rothbaum BO, Ninan PT. The assessment of trichotillomania. Behav Res Ther 1994;32(6):651-62.

4. Diefenbach GJ, Tolin DF, Crocetto J, et al. Assessment of trichotillomania: a psychometric evaluation of hairpulling scales. J Psychopathol Behav Assess 2005;27 (3):169-78.

5. Cohen S, Williamson G. Perceived stress in a probability sample of the United States. In S. Spacapan \& S. Oskamp (Eds.), The social psychology of health: Claremont Symposium on applied social psychology. Newbury Park CA. 1988.

6. WHOQOL Group. Development of the world health organization. WHOQOL-BREF quality of life assessment. Psychol Med 1998;28(3):551-8. 